\title{
Postheparin plasma diamine oxidase values in the follow up of patients with small bowel Crohn's disease
}

\author{
L D'Agostino, S Pignata, B Daniele, M Visconti, C Ferraro, G D'Adamo, \\ G Tritto, G Ambrogio, G Mazzacca
}

\begin{abstract}
Measurement of postheparin plasma diamine oxidase (PHD) activity has been proposed to assess mucosal integrity in several diseases of the small intestine. In Crohn's disease, PHD values identify a group of patients with predominantly small bowel mucosal damage. To determine the role of mucosal involvement in the progression of small bowel Crohn's disease and whether different PHD values can predict different outcomes the changes in PHD values in 41 patients with small bowel Crohn's disease admitted consecutively to our department were investigated. The test was performed during periods of active disease and after either medical or surgical treatment had resulted in improvement. PHD values were significantly lower than in normal subjects (normal range 3.7-7.7 $\mathrm{U} / \mathrm{ml})$. In 35 patients with active disease (Crohn's disease activity index (CDAI) $>150$ ) two groups were identified by choosing a cut off value of $2 \mathrm{U} / \mathrm{ml}: 93 \%$ of the 15 patients with PHD values lower than $2 \mathrm{U} / \mathrm{ml}$ (mean (SD) $1.36(0.46) \mathrm{U} / \mathrm{ml})$ relapsed at least once in the following year, while only the $20 \%$ of the 20 whose values were higher than $2 \mathrm{U} / \mathrm{ml}$ (mean (SD) $3.69(1.50)$ ) relapsed in the same period. The data were statistically significant (Yates's corrected $\left.\chi^{2}=15.63 ; \mathrm{p}<0.0001\right)$. The positive and negative predictive values of the test were $93 \%$ and $80 \%$, respectively. During relapses, PHD values were consistently lower than previous values, and increased significantly after effective medical or surgical treatment. In the six patients in whom there were no changes in disease activity (CDAI persistently $<150$ ), there was no change in PHD values. This test may be useful for identifying Crohn's disease patients who are likely to relapse. Furthermore, the data indicate that mucosal damage is common in active small bowel Crohn's disease and improves at least in part after treatment.
\end{abstract}

The course of Crohn's disease is extremely unpredictable. Although some patients have frequent relapses, up to $20 \%$ have no further episodes for as long as 20 years after the first, or even the second. ${ }^{1}$ Very little is known about the factors that determinate the different outcomes of the disease, nor has the role of mucosal damage in the progression of the disease ever been investigated.

Numerical indices are generally used to assess the disease activity and the severity of the relapses. ${ }^{2}$ None of the indices, however, correlates with the subsequent outcome. ${ }^{3}$

In the past few years there have been several reports on the usefulness of the postheparin plasma diamine oxidase (PHD) test in evaluating small intestinal mucosa integrity. ${ }^{+10}$ The test is based on the ability of heparin to release the enzyme diamine oxidase (DAO) from the small intestinal mucosa into the circulation. ${ }^{11-13}$ Since the enzyme is synthesised by the differentiated and non-proliferating enterocytes, $"$ its plasma activity after an intravenous injection of heparin correlates with the morphological integrity of the small intestinal epithelium. ${ }^{+5101+}$ The test proved to be helpful in quantitating the remaining mature enterocyte mass in patients with coeliac disease before ${ }^{46}$ and after $^{5}$ gluten free diet, in small bowel lymphoma, ${ }^{+10}$ and in Crohn's disease. $^{78}$

In the last group, PHD values were significantly lower than in normal subjects and correlated inversely with the Crohn's disease activity index (CDAI), ${ }^{7-9}$ while no correlation was found with the radiological extent of the disease. ${ }^{7}$ The test was able to identify a cluster of patients with predominant involvement of the mucosal layer. This finding prompted us to investigate whether different PHD values can predict different disease outcomes. In addition, since we had previously observed in a small number of patients with active disease that PHD values increased after anti-inflammatory treatment, ${ }^{7}$ we also wished to investigate the changes in PHD values during clinical relapse and after medical or surgical treatment in a larger series of patients to clarify the importance of mucosal involvement in the progression of small bowel Crohn's disease.

\section{Methods}

PATIENT SAMPLE AND EXPERIMENTAL DESIGN We studied 41 patients ( 21 men, 20 women; mean (SD) age 36 (12) years) with small bowel Crohn's disease (12 ileal, five diffuse small bowel disease, and 24 ileocolonic disease) consecutively admitted to our department in the last five years. Diagnosis of Crohn's disease was made by us in 20 patients but in the other 21 we confirmed a diagnosis made elsewhere. Activity of the disease was assessed by the CDAI. ${ }^{\text {" }}$

In all patients, the PHD test was performed for the first time at admission to our department and then when the disease relapsed (CDAI $>150)$. In the six patients in whom there were no changes in 
disease activity (CDAI persistently lower than 150 ), the test was repeated every six months.

PREDICTION OF RELAPSE OCCURRENCE

The PHD test was carried out in 35 patients with CDAI $>150$. Fifteen patients in this group presented with active disease at hospital admission and 20 had clinical relapses during follow up. These patients were divided in two groups according to the PHD value recorded in the active phase (group A: $\mathrm{PHD}<2 \mathrm{U} / \mathrm{ml}$; group B: PHD $>2 \mathrm{U} / \mathrm{ml}$ ) in order to investigate whether different PHD values can predict different disease outcomes. To this end we evaluated the occurrence of clinical relapses over one year in each group. Follow up started after clinical improvement $($ CDAI $<150)$ induced by antiinflammatory drugs and supportive therapy administered according to the National Cooperative Crohn's Disease Study criteria. ${ }^{16}$

\section{CHANGES IN PHD VALUES AFTER TREATMENT}

To verify the effectiveness of treatment in the recovery of small bowel mucosal integrity, the test was repeated in 23 patients with active disease two to three months after clinical improvement (CDAI <150) resulting from medical treatment. In six patients who subsequently underwent intestinal resection, the PHD value was assessed before and six months after surgery.

\section{PHD TEST AND DAO ASSAY}

Heparin (15000 IU) was administered by intravenous bolus. Blood $(7 \mathrm{ml})$ was drawn 60 minutes after the injection, collected in heparinised tubes, and centrifuged at $3000 \mathrm{~g}$. The plasma was stored at $-20^{\circ} \mathrm{C}$ and assayed for DAO within a week. To simplify the test, plasma DAO activity was assessed only in the blood sample taken 60 minutes after heparin injection instead of in the several samples necessary for the calculation of the area under a 0-120 minute curve, as described in our previous study. ${ }^{7}$ In fact, the 60 minute sample correlates very well with the corresponding area under the curve and is the best discriminator among patients with different intestinal diseases. ${ }^{17} \mathrm{DAO}$ was assayed in triplicate by a ${ }^{14} \mathrm{C}$-putrescine method as described in a previous study. ${ }^{17}$

DAO activity was expressed as $\mathrm{U} / \mathrm{ml}(1 \mathrm{U}=1$ nmol of putrescine dihydrochloride oxidised for 1 hour at $\left.37^{\circ} \mathrm{C}, \mathrm{pH} 7 \cdot 2\right)$. The normal range $(44$ subjects) is $3 \cdot 7-7 \cdot 7 \mathrm{U} / \mathrm{ml}$; mean $(2 \mathrm{SD})=5 \cdot 3(2)$ $\mathrm{U} / \mathrm{ml}$.

In each patient, liver function (prothrombin time, alanine aminotransferase, bilirubin, alkaline phosphatase) was tested to avoid the possibility of impaired liver uptake of DAO causing high plasma DAO values that were not related to mucosal integrity. ${ }^{18}$ No abnormalities were found.

Written informed consent was obtained from all patients. No complication resulted from the administration of heparin.

In all subjects partial thromboplastin time (PTT) was monitored. Three hours after the beginning of the test, PTT was still $2-2 \cdot 5$ times the maximum value of the normal range (22-44 seconds). It returned to normal within five hours of heparin injection.

Whenever the test was performed as an outpatient procedure, patients were allowed to leave the hospital four hours afterwards.

\section{STATISTICAL ANALYSIS}

Differences in PHD values before and after treatment were evaluated by Student's $t$ test for paired data. Differences in outcomes of patients and the relative risk of relapse in the two groups of patients were assessed by the $\chi^{2}$ test using the EPIINFO version 5 (Public Domain Software for Epidemiology and Disease Surveillance). Results are expressed as mean (SD) and differences were considered statistically significant when $\mathrm{p}<0.05$.

\section{Results}

PHD values recorded in the active phase of the disease in patients who relapsed during the one year follow up and in those who did not were $2 \cdot 1$ $(1 \cdot 8)$ and $3 \cdot 3(1 \cdot 2) \mathrm{U} / \mathrm{ml}$ respectively. Choosing a PHD cut off value of $2 \mathrm{U} / \mathrm{ml}$ we identified two groups of patients; 14 out of 15 patients (group A) whose PHD values were lower than $2 \cdot 0(1.36$ $(0 \cdot 46) \mathrm{U} / \mathrm{ml})$ during the active phase of the disease relapsed at least once in the following year, while only four of the 20 patients (group B) with PHD values above $2.0(3.69(1.5) \mathrm{U} / \mathrm{ml})$ relapsed during follow up (Table). The mean PHD values of the A and B groups of patients were significantly different $(p<0.001)$.

The average treatment time required for clinical recovery ranged from one to three months and was not different in the two groups studied.

Using the $2 \mathrm{U} / \mathrm{ml}$ cut off value, the test sensitivity and specificity in identifying the patients who are likely to relapse were $77 \%$ and $94 \%$ respectively; the positive and negative predictive values of the test were $93 \%$ and $80 \%$ respectively.

The Yates's corrected $\chi^{2}$ value was $15 \cdot 63$, with $\mathrm{p}<0.0001$. The relative risk (RR) of relapse in patients with a PHD value $<2 \mathrm{U} / \mathrm{ml}$ was $=4.67$ $(1.92<\mathrm{RR}<11.33)$

Biochemical markers of inflammation such as $C$ reactive protein, erythrocyte sedimentation rate, and blood white cell counts, performed during the active phase, were not significantly different in patients who relapsed within 12 months and in those who did not. Thus, these indices were not useful in predicting patient outcomes.

During follow up we performed the PHD test

Clinical relapses in 35 patients with active small bowel Crohn's disease according to plasma diamine oxidase values after iv heparin (PHD)

\begin{tabular}{lll}
\hline & Group A & Group B \\
\hline PHD values (mean (SD)) & $1 \cdot 36(0 \cdot 46)$ & $3 \cdot 69(1 \cdot 5)$ \\
No of patients & 15 & 20 \\
No of relapsed patients/year & 14 & 4 \\
\hline
\end{tabular}

Group A: PHD $<2 \mathrm{U} / \mathrm{ml}$; group B: PHD $>2 \mathrm{U} / \mathrm{ml}$.

(Yates's corrected $\chi^{\prime}=15.63 ; \mathrm{p}<0.0001$.) 


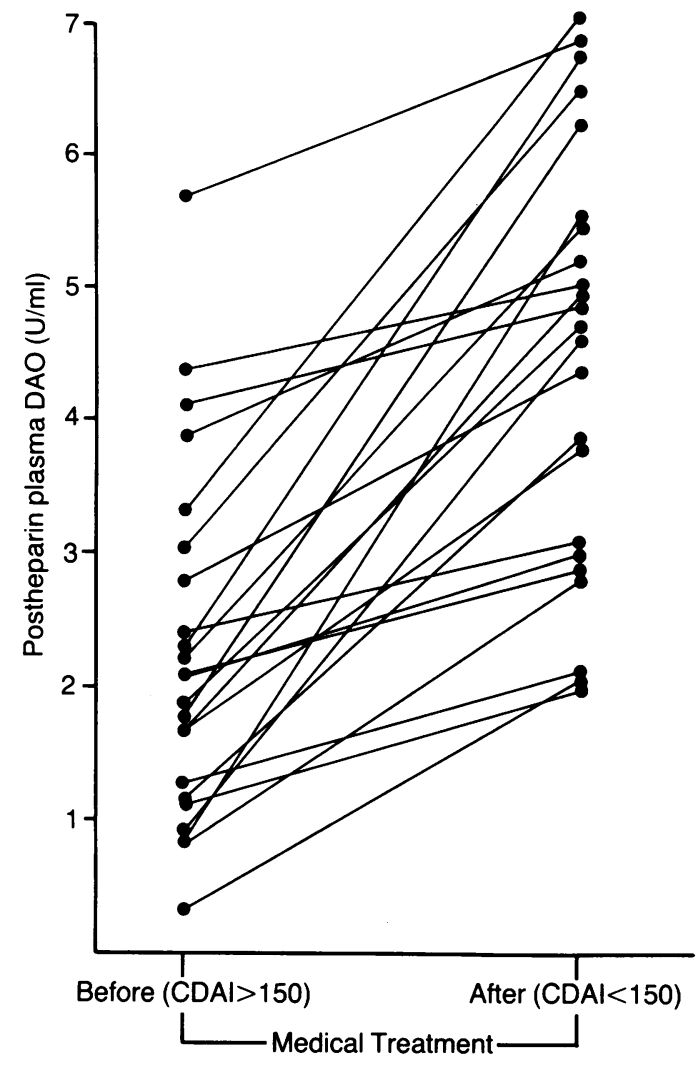

Figure 1: Changes in plasma diamine oxidase (DAO) values after iv heparin induced by clinically effective antiinflammatory treatment in 23 patients with small bowel Crohn's disease. Differences in mean values are statistically significant $(p<0.001)$. CDAI=Crohn's disease activity index.

in 22 patients who relapsed. In all but two PHD values fell consistently: the drop ranged between $23-80 \%$ in respect of basal values (data not shown).

A significant increase in PHD values $(\mathrm{p}<0.001)$ was recorded in the 23 patients in

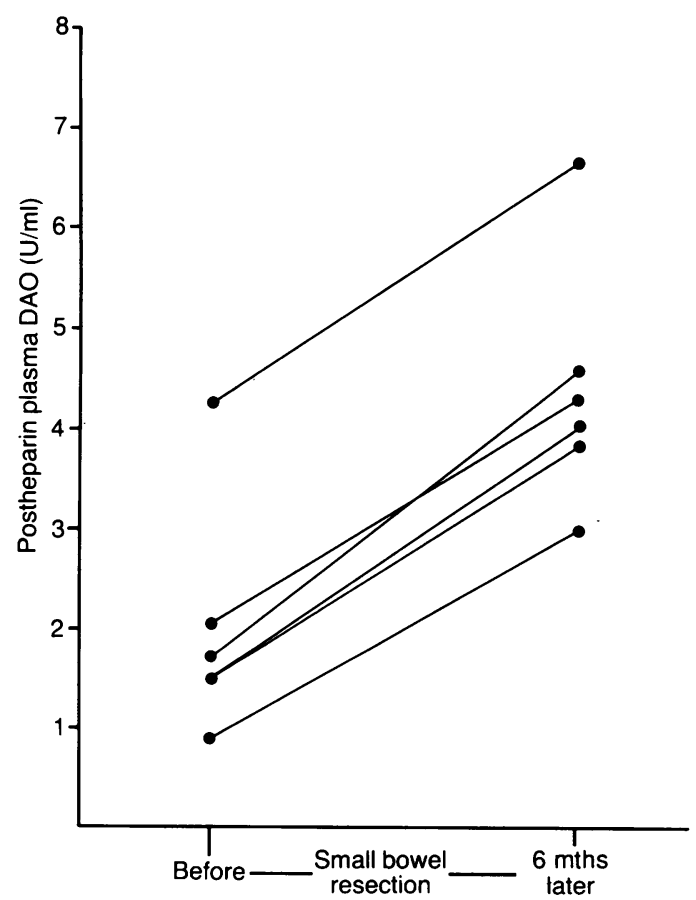

Figure 2: Changes in plasma diamine oxidase $(D A O)$ values after iv heparin induced by surgery in six patients with small bowel Crohn's disease. Differences in mean values are statistically significant $(p<0.001)$. whom the test was repeated after remission induced by anti-inflammatory treatment. Values before and after treatment were $2 \cdot 30(1 \cdot 33)$ and $4.44(1 \cdot 62) \mathrm{U} / \mathrm{ml}$, respectively (Fig 1).

Five patients underwent resection because of complications (three had intestinal obstruction, one abdominal abscess, and one ileocolonic fistula). One additional patient whose disease remitted after medical treatment, needed to be operated on for intestinal obstruction 12 months later. Figure 2 shows the PHD values in these six patients before and six months after surgery. A significant $(p<0.001)$ increase in PHD was observed in all patients.

Six patients whose disease was not active when admitted to our department did not relapse over a mean (SD) follow up period of $38.6(17.6)$ months; their PHD values $(4 \cdot 5(1 \cdot 1) \mathrm{U} / \mathrm{ml})$ did not change during the follow up.

The specificity of the test for small bowel mucosal damage in Crohn's disease was confirmed by the low PHD values in two patients with Crohn's colitis in whom unsuspected ileal involvement was subsequently found. Normal values were observed in a patient with Crohn's colitis only and in a group of six patients with idiopathic proctocolitis (unpublished data).

\section{Discussion}

The results of this study show that PHD, a marker of mucosal damage in patients with small bowel Crohn's disease, ${ }^{7}$ can be used for identifying patients who are likely to relapse. Furthermore, this test may be useful in assessing the response to treatment and in following the recovery of mucosal integrity in Crohn's disease patients.

PHD has been proposed as a new test to assess the morphological and functional integrity of the small bowel mucosa. ${ }^{19}$ The blood measurement of an enzyme activity that is almost exclusively of small intestinal origin ${ }^{2021}$ and that correlates with the differentiated enterocytic mass ${ }^{5}$ represents a new approach to the evaluation of diseases affecting the small intestinal mucosa, the assessment of which is otherwise based on clinical tests of digestion and absorption. ${ }^{22}$ In Crohn's disease results of absorption tests may be affected by bacterial overgrowth rather than mucosal damage, thus making the assessment of mucosal lesions difficult. Thompson $e t a l^{23}$ found that in resected specimens of small bowel from patients with Crohn's disease, mucosal DAO activity correlated inversely with histological grading of the severity of inflammatory changes.

In the present study, PHD values decreased when Crohn's disease patients relapsed, indicating that mucosal damage is very common during the active phase of the disease and suggesting that mucosal involvement may be an important factor in determining clinical relapse. The ability to predict, with some degree of confidence, whether or not Crohn's disease will recur in an individual patient would be valuable because it would provide a better basis for decisions about treatment. To this end, there have been studies of prophylactic steroid treatment ${ }^{24} 25$ in subsets of patients with a high risk of relapse. ${ }^{26}$

This study showed that patients with very low 
PHD values during active disease had a poorer prognosis and suggests that the PHD test may have a role in the prediction of short term relapses in patients with small bowel Crohn's disease. If our results are confirmed in a larger series of patients and over a longer follow up, it will be interesting to study subsets of patients with Crohn's disease and very low PHD values to see if they benefit from prophylactic treatment.

Furthermore, our data indicate that effective drug treatment restored, albeit partly in some patients, intestinal DAO values.

Surgery, performed in six patients for complications, also caused an increase in the PHD values six months after the operation. The higher PHD values after surgery may be a result of restoring mucosal integrity after the removal of inflamed gut and the resumption of the luminal nutrition, which has a trophic effect. ${ }^{27}$ Moreover, the resection of part of the bowel may have induced an adaptive response that quickly increases functional capability. ${ }^{28}$ In fact, resection is a strong stimulus to compensatory growth of the small bowel. ${ }^{2930}$ After partial resection the villi become hyperplastic and this persists for at least three to six months, and probably indefinitely. ${ }^{30}$ Furthermore, increased DAO values were detected in the small bowel mucosa of rats which underwent intestinal resection. ${ }^{31}$

In conclusion, we have confirmed low PHD values in patients with active Crohn's disease. Treatment, either medical or surgical, increased PHD values, indicating that mucosal damage is common during active disease but can be repaired by therapy. Patients with very low PHD values had a poorer prognosis in terms of number of relapses, suggesting that mucosal lesions are important in the progression of the disease.

The authors thank Dr F Romano for helpful suggestions, Ms Carla Perrot, Patrizia Ferro, and Carla Mautone for nursing assistance, and Mr Pasquale Esposito for technical assistance. Dr Sandro Pignata is recipient of a fellowship from AIRC (Associazione Italiana per la Ricerca sul Cancro). Dr Bruno Daniele is supported by a fellowship from Dotorato di Ricerca in Scienze Gastroenterologiche, Università di Roma 'La Sapienza.'

1 Donaldson RM jr. Crohn's disease. In: Sleisenger $\mathrm{MH}$ Fordtran JS, eds. Gastrointestinal disease. Philadelphia: Saunders, 1989: 1327-58.

2 Pallone F, Ricci R, Boirivant M, Montano S. Measuring the 'activity' of Crohn's disease. Ital f Gastroenterol 1981; 13:513.

3 De Dombal FT, Softley A. Surgical treatment of Crohn's disease in the 1980s. A discussion of some strategical and tactical problems. In: Dobrilla G, Bertaccini G, Langman MJS, et al, eds. Problems and controversies in gastroenterology. New York: Raven Press, 1986: 145-51.

4 D'Agostino L, Ciacci C, Daniele B, Barone MV, Sollazzo R, Mazzacca G. Postheparin plasma diamine oxidase in subjects with small bowel mucosa atrophy. Dig Dis Sci 1987; 32: 3137.

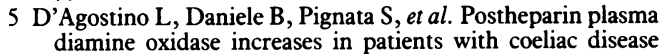
during gluten free diet. Gut 1987; 28 (suppl): 13l-4.

6 Corazza GR, Falasca A, Strocchi A, Rossi CA, Gasbarrini G.
Decreased plasma postheparin diamine oxidase levels in celiac disease. Dig Dis $S$ ci 1988; 33:956-61.

7 D'Agostino L, Daniele B, Pallone F, Pignata S, Leoni M Mazzacca G. Postheparin plasma diamine oxidase in patients with small bowel Crohn's disease. Gastroenterology 1988; 95 1503-9.

8 Thompson JS, Burnett DA, Cormier RA, Vaughan VP. Plasma postheparin diamine oxidase activity. Development of a simple technique of assessing Crohn's disease. Dis Colon Rectum 1988; 31: 529-32.

9 Rokkas T, Vaja S, Murphy GM, Dowling RH. Postheparin plasma diamine oxidase in health and intestinal disease. plasma diamine oxidase in health and
Gastroenterology 1990; 98: 1493-501.

10 D'Agostino L, Contegiacomo A, Pignata S, et al. Plasma postheparin diamine oxidase in patients with small intestina lymphoma. Cancer 1991; 67: 511-5.

11 Shakir KM, Margolis S, Baylin SB. Localization of histaminase (diamine oxidase) in rat small intestinal mucosa: site of release by heparin. Biochem Pharmacol 1977; 26: 2343-7.

12 D'Agostino L, Daniele B, Pignata S, D'Argenio G, Mazzacca G. Modification in enterocyte diamine oxidase distribution induced by heparin in the rat. Biochem Pharmacol 1989; 38 : $47-9$.

13 D'Agostino L, Pignata S, Daniele B, et al. Release of diamine oxidase into plasma by glycosaminoglycans in rats. Biochim oxidase into plasma by glycosam
Biophys Acta 1989; 993: 228-32.

14 Luk GD, Bayless TM, Baylin SD. Plasma postheparin diamine oxidase. Sensitive provocative test for quantitating length of acute intestinal mucosa injury in the rat. $\mathcal{F}$ Clin Invest 1983 71: 1308-15

15 Best WR, Becktel JM, Singleton JW, Kern F. Development of a Crohn's disease activity index: National Cooperative Crohn's Disease study. Gastroenterology 1976; 70: 439-44.

16 Summers RW, Switz DM, Sessions JT, et al. Nationa Cooperative Crohn's Disease study: results of drug treatment. Gastroenterology 1979; 77: 847-69.

17 D'Agostino L, Daniele B, Pignata S, Greco L, Mazzacca G. Postheparin plasma diamine oxidase in subjects with small powel disease. Diagnostic efficiency of a simplified test. Digestion 1988; 41: 46-54.

18 D'Agostino L, Ciacci C, Capuano G, et al. Metabolic fate of plasma diamine oxidase: evidence of isolated and perfused rat liver uptake. Digestion 1986; 34: 243-50

19 D'Agostino L, Ciacci C, Daniele B, Barone MV, Sollazzo R Mazzacca G. Plasma diamine oxidase (DAO) and heparin [Letter]. Dig Dis Sci 1984; 29: 1070-1.

20 Kobayashi Y, Kupelian J, Maudsley DV. Release of diamine oxidase by heparin in the rat. Biochem Pharmacol 1969; 18: 1585-91.

21 Rokkas T, Vaja S, Taylor P, Murphy GM, Dowling RH. Is the intestine the sole source of heparin-stimulated plasma intestine the sole source of heparin-stimulated plasma diamine oxidase? Acute effect of jejunectomy, ileectomy and

22 Wright TL, Heyworth MF. Maldigestion and malabsorption. Wright TL, Heyworth MF. Maldigestion and malabsorption
In: Sleisenger MH, Fordtran JS, eds. Gastrointestinal disease. Philadelphia: Saunders, 1989: 263-82.

23 Thompson JS, Burnett DA, Martin RS, Vaughan WP Intestinal mucosa diamine oxidase activity reflects intestina involvement in Crohn's disease. Am $\mathcal{F}$ Gastroenterol 1988; 83 . $756-60$.

24 Brignola $C$, Campieri $M$, Farruggia $P$, et al. The possible utility of steroids in the prevention of relapses of Crohn's disease in remission: a preliminary study. $\mathcal{F}$ Clin Gastroenterol 1988; 10 : 631-4.

25 Malchow H, Ewe K, Brandes JW, et al. European Cooperative Crohn's Disease Study (ECCDS): results of drug treatment. Gastroenterology 1984; 86: 249-66.

26 Brignola C, Campieri M, Bazzocchi G, Farruggia P, Tragnone $A$, Lanfranchi GA. A laboratory index for predicting relapse in asymptomatic patients with Crohn's disease. Gastro enterology 1986; 91 : $1490-4$.

27 Dowling RH, Booth CC. Structural and functional changes following small intestinal resection in the rat. Clin Sci 1967 32: $132-49$.

28 Williamson RCN. Intestinal adaptation. Structural, functional and cytokinetic changes. $N$ Engl f Med 1978; 298: 1393and 402 .

29 Luk GD, Baylin SD. Polyamines and intestinal growth increased polyamine biosynthesis after jejunectomy. Am $\mathcal{F}$ increased polyamine biosynt

30 Williamson RCN. Intestinal adaptation: factors that influence morphology. In: Polak JM, Bloom SR, Wright NA, Daly MJ, eds. Structure of the gut. Ware, Herts: Glaxo Group Research Limited, 1982: 337-45.

31 Buts JB, Theys SD, De Keyser N, Dive C. Changes in serum and intestinal diamine oxidase (DAO) activity after proximal enterectomy in rats. Correlation of DAO activity with mucosal mass parameters. Dig Dis Sci 1989; 34: 1393-8. 